\title{
Unique contribution of shared book reading on adult-child language interaction
}

\author{
Lucy F. CLEMENS and Cornelia A. T. KEGEL* \\ Leiden University, Netherlands \\ ${ }^{*}$ Corresponding author: Universiteit Leiden - Sociale Wetenschappen, Wassenaarseweg 52, Leiden 2300 \\ RA, Netherlands email: ckegel@fsw.leidenuniv.nl
}

(Received 19 July 2019; revised 5 February 2020; accepted 13 May 2020;

first published online 11 June 2020)

\begin{abstract}
Researchers agree that early literacy activities, like book sharing and parent-child play, are important for stimulating language development. We hypothesize that book sharing is most powerful because it elicits more interactive talk in young children than other activities. Parents of 43 infants (9-18 months) made two daylong audio recordings using the LENA system. We compared a typical day, with spontaneous occurring activities, with an instructed day when caregivers were prompted to do book reading and toy play. Book sharing resulted in a combination of more parent talk, child talk, and interactions than other language activities. Research context did not influence outcomes: no differences were found in language use between the spontaneous and the instructed activities. Overall it seems clear that even with infants shared reading is a strong unique stimulator of language use from parent and child.
\end{abstract}

Keywords: language development; language input; adult-child language interaction; book sharing; parent-child play; LENA; natural language environment; quality time; infants; research context

\section{Introduction}

Shared book reading is found to be important for children's language development (Flack, Field \& Horst, 2018; Noble, Sala, Peter, Lingwood, Rowland, Gobet \& Pine, 2019), emergent literacy, and reading skills (Mol \& Bus, 2011). That shared reading is such an important activity is noteworthy since it is a relatively small activity, constituting at most 1-2 percent of a child's daytime experience (Soderstrom \& Wittebolle, 2013). This begs the question of why book sharing typically influences language development, if it is such a small part of a child's day. It is suggested that small amounts of shared book reading have strong effects on language development due to the quality of the language input during book sharing. It is, for instance, a fact that picture books are a rich source of vocabulary for young children as individual picture books generally contain more unique word types than length-matched, child-directed conversations (Montag, Jones \& Smith, 2015). Moreover, the language that parents use around shared book reading is found to be

(C) The Author(s), 2020. Published by Cambridge University Press. This is an Open Access article, distributed under the terms of the Creative Commons Attribution licence (http://creativecommons.org/licenses/by/4.0/), which permits unrestricted re-use, distribution, and reproduction in any medium, provided the original work is properly cited. 
more complicated, containing more diverse vocabulary, different types of verbs, and a longer mean length of utterances, compared to language used in interactions with their children outside book reading (Demir-Lira, Applebaum, Goldin-Meadow \& Levine, 2019). In addition, a direct comparison of book reading sessions and play sessions showed book reading to generate more grammatically enriched linguistic input compared to traditional toy play with even the most simple one word per page book (Noble, Cameron-Faulkner \& Lieven, 2018). The difference in language input received via shared book reading may increase to nearly 300,000 unique words heard by the age of five between children who are read to once per day and children who are never read to (Logan, Justice, Yumuş \& Chaparro-Moreno, 2019).

In this study, targeting infants, we explore the hypothesis that the key difference between book sharing and other activities may be found in the degree of adult-child interaction during shared reading (Hart \& Risley, 1995; Suskind, Suskind \& LeWinter-Suskind, 2015). There is evidence showing that parent-child language interaction stimulates language development more than just language input (Gilkerson, Richards, Warren, Oller, Russo \& Vohr, 2018; Greenwood, Thiemann-Bourque, Walker, Buzhardt \& Gilkerson, 2011; Ramírez-Esparza, García-Sierra \& Kuhl, 2014; Rowe, 2012; Warlaumont, Richards, Gilkerson \& Oller, 2014; Zimmerman, Gilkerson, Richards, Christakis, Xu, Gray \& Yapanel, 2009). The key elements to support children's vocabulary development may be found in the one-to-one context where parents can respond to infants contingently (Ramírez-Esparza et al., 2014) and the nuanced aspects of adult-child interactions (Rowe \& Zuckerman, 2016). Book sharing in particular seems to be a rich source for verbal interaction (e.g., Gilkerson, Richards \& Topping, 2017; Mol, Bus, de Jong \& Smeets, 2008; Whitehurst, Falco, Lonigan, Fischel, DeBaryshe, Valdez-Menchaca \& Caulfield, 1988). It offers a warm and enjoyable context for interaction between parent and child (Logan et al., 2019), as well as a high level of joint attention which is positively related to language development for children as young as 9 months old (Farrant \& Zubrick, 2012).

Some studies have compared language input and parent-child interactions during shared book reading with other types of parent-child activities using the Language Environment Analysis (LENA) system (Gilkerson et al., 2017; Soderstrom \& Wittebolle, 2013; Sosa, 2016). With the LENA recording device it is possible to collect natural data in large samples, providing an easy way to study the differences in language input and interaction during book sharing and other common activities (Tamis-LeMonda, Kuchirko, Luo, Escobar \& Bornstein, 2017). Soderstrom and Wittebolle (2013) examined language input in the home environment among one- and two-year-old children. They found that book reading elicits as many adult words as organized play and that both activities provoke more adult words compared to any other activity inside the home environment. In her study with infants of 10 to 16 months old, Sosa (2016) instructed parents to play with electronic and traditional toys and to read books with their infant. In her study, book reading elicited more adult language input as compared to parent-child play with either toys. The number of conversational turns was similar for book reading and parent-child play with traditional toys. However, both activities elicited more conversational turns than parent-child play with electronic toys. Gilkerson et al. (2017) also found book sharing to be superior to other activities in generating language input from parents to older children (2-5 years). In addition, book sharing was found to elicit more conversational turns. It should however be noted that only book sharing was examined as a specific activity in this study, while no distinction was made between activities that may also elicit parent-child interaction like toy play. 
We studied whether book reading is an unique tool in creating a rich language environment compared to other language related parent-child activities. We focused especially on infants, because the foundation for later language development is built at the start of life. Infants' brains are prepared for learning and become tuned to their native language in the first year of life (Kuhl, 2004). High quality language stimulation is required to form a sensitive language system where subsequent experiences can build on (Tierney \& Nelson, 2009). We therefore examined which language activities are specifically beneficial to enrich the language environment of an infant. Only Sosa's study (2016) focused on such a young age group; however, her study captured only two different language activities. The other studies that compared language input and parent-child interactions so far focused on older children (Gilkerson et al., 2017; Soderstrom \& Wittebolle, 2013).

We were also interested in the possible influence of the research context on the language environment measured. By using the LENA system we minimized the potential artifacts introduced by the presence of an observer or parents' reactions to a laboratory setting (Weisleder \& Fernald, 2013). However, studies that make parents explicitly aware of the focus of the study, e.g., by explicit instructions to read or play with the child (Sosa, 2016) or register how many times a child is read to (Gilkerson et al., 2017), may result in different language outcomes than studies that capture natural day recordings without instructions. We argue that making parents aware of the focus of the study may result in different language outcomes than capturing natural day recordings without instructions. To gain insight in this possible influence of the research context on the measured language environment we included two different designs. On the first day of recording, we did not influence parent-child activities, while on the second day we asked parents to engage in a book reading session and a parent-child play session.

Our research targeted the following questions:

1) Does the number of adult words, infant vocalizations, and conversational turns between adult and child during shared book reading differ from other everyday activities in which an adult is involved: parent-child play with toys, singing songs, reciting rhymes, personal care, and mealtime?

2) Does book sharing and parent-child toy play, if invited by the researcher, result in similar language use between parent and child as compared to spontaneous performance of these activities?

\section{Method}

\section{Design}

Enrollment and data collection occurred over a 16-month period between November, 2015 and February, 2017. Written informed consent was obtained from parents beforehand, which included explicit consent to listen to the recordings. Informed consent was provided by the parents both for themselves and on behalf of their child. They were given the opportunity to withhold certain fragments of their recording from the experiment, which happened six times in 86 recorded days. Both recording days, the LENA device registered a whole day. The first day was a typical day, where parents did not receive a task, while, on the second day, parents were instructed to read and play, at least once, with their child and report on a provided form when this happened. 


\section{Participants}

A volunteer sample of parent-infant dyads was recruited through posting of flyers in a daycare center and via social media. Participants were 43 infants ( $51 \%$ boys) between the ages of 9 and 18 months and their parents. At the two days the LENA recordings took place, children were on average 13 months ( $S D=3.02$ months) and 15 months ( $S D=2.27$ months) old. Children attended daycare or had a babysitter for an average of 21.7 hours a week, ranging from 4 to 32 hours. Most mothers had completed higher education (79\%), as did most of the fathers $(74 \%)$.

\section{Procedure}

The recording equipment used was the LENA Pro System (Language ENvironment Analysis; LENA Foundation). All participating families were visited twice. The first visit took place when the child was at least 9 months old. During this visit, a questionnaire was administered to gather information about background variables. Also, instructions were given for using the LENA recorder. The first recording was administered on a regular day when the parent was at home with the child. Parents were instructed to start the recording when the child wakes up in the morning and record for at least 10 successive hours. The recorder had to be nearby when the child was taking a nap or having a bath.

After completing the first recording day, parents were visited for a second time to give additional instructions for the second recording day. Due to practical reasons the second recording day took place approximately two months after the first recording. During the second recording day, parents were instructed to read and play with their child, perform both activities at least once, and to report when these activities were performed. Parents could choose one of their own books that they enjoyed to read to their child or a book provided by the researchers. All parents preferred a book of their own. Because of the influence of type of toy on the language interaction (Sosa, 2016), we provided all parents with the same toy. This toy was chosen for its expected possibility to initiate interaction: a set of stacking cups in different colors and with animal faces on the bottom of the cups.

\section{LENA system}

The LENA system is a lightweight, highly durable, wire-free, and high-quality recording device designed to be worn by an infant as they proceed through their regular day for at least 10-12 successive hours. The LENA system uses a Digital Language Processor (DLP) specifically designed to record the language environment of infants and toddlers (Ford, Baer, Xu, Yapanel \& Gray, 2008). The DLP was worn by the child, in a t-shirt with a special pocket. The detection process of the LENA system is based on phone-decoding - that is, analyzing the vowels and consonants uttered, which makes it possible to code adult speech and child vocalizations in different languages (Xu, Yapanel, Gray, Gilkerson, Richards \& Hansen, 2008). The software of the LENA system automatically analyses the recording and calculates the number of words spoken by an adult in proximity of the child (Adult Word Count, AWC), the number of speech-like vocalizations of the child (Child Vocalizations, CV), and the number of times the child and adult reacted to each other within 5 seconds (Conversational Turns, CT). These language scores were calculated for 5 minute 
units (Gilkerson \& Richards, 2008). Speech that occurred under noisy conditions (e.g., overlapping with another speaker) or too quiet/distant was excluded from analysis by the LENA system (for more information see $\mathrm{Xu}$ et al., 2008). The LENA has been proved reliable in English (Xu, Yapanel \& Gray, 2009), French (Canault, Le Normand, Foudil, Loundon \& Thai-Van, 2016), and Spanish (Weisleder \& Fernald, 2013).

\section{Coding}

\section{Activity categories}

Adult-child activities were coded in 5-minute units. The coding of activities was done according to a clearly defined list of everyday occurring activities. This list of activities was based on the study of Soderstrom and Wittebolle (2013) and adjusted to the sample in this study. The list included the following activities: book reading, singing songs, toy play, personal care, and mealtime (see Table 1 for the activities and their definition).

\section{Sampling procedure}

The total duration of all the recordings for the first recording day was 467 hours, resulting in 5604 5-minute units. To decrease the number of 5-minute units to encode, we selected a representative sample of units. We chose every $5^{\text {th }}$ (5-minute) unit and tested whether this selection method resulted in a valid reflection of activities throughout the day. To check the validity of this selection method we divided one recording into three different samples using three different starting points. After scoring and comparing the activities for each of these samples we found similar results indicating the selection method to be representative. So, for the first recording day, each $5^{\text {th }}$ (5-minute) unit of the day recordings were selected with a maximum up to 12 hours. This resulted in an average of 20.4 fragments per recording (range: 14 to 27 ) and a total of 897 coded 5-minute-units.

For the second recording day, only the 5-minute units related to book reading and parent-child play sessions were included. The parents' report on when they performed these activities (time of day) were used to find the 5-minute units in which book reading and toy play took place. If book sharing or play covered more than one 5-minute unit, all related 5-minute units were coded.

\section{Coding}

Seven trained coders (master students) assigned activities to each selected 5-minute unit of the first recording day. When more activities took place during a 5-minute unit, all activities were coded. Units that did not include an activity on the list were not coded. The inter-coder agreement between the coders and the first author on 55 five-minutes units (275 minutes) ranged from a Cohen's kappa that equalled 0.71 for toy play to a Cohen's kappa of 1.00 for book sharing (see Table 1).

\section{Language measures}

For all coded 5-minute units of both recording days, we retrieved LENA-scores on adult word count (AWC), child vocalizations (CV), and conversational turns (CT). The scores on AWC, CT, and CV were averaged per activity. It should be noted that often two or more activities were assigned to a 5-minute unit. In those cases, all coded activities received the same scores. For example, if a parent sang a song while 
Table 1. Definitions of the activity categories used for coding and their inter-coder reliability

\begin{tabular}{llc}
\hline Activity & \multicolumn{1}{c}{ Description } & $\begin{array}{c}\text { Cohen's } \\
\text { Kappa }\end{array}$ \\
\hline Book reading & Adult is reading a book to the child. & 1.00 \\
\hline Toy play & Child and adult are playing with a toy or object. & 0.71 \\
\hline Singing songs & $\begin{array}{c}\text { Adult sings a children's song, including singing along with } \\
\text { children's songs on CD, or saying a nursery rhyme. }\end{array}$ & 0.87 \\
\hline Mealtime & $\begin{array}{c}\text { From the time of sitting down at the table until leaving the table, } \\
\text { including snacks and drinks in between. }\end{array}$ & 0.79 \\
\hline Personal care & $\begin{array}{c}\text { Dressing, diaper changing, cleaning nose, washing face, bath } \\
\text { time etc. }\end{array}$ & 0.82 \\
\hline
\end{tabular}

brushing the child's teeth during a 5-minute unit, both activities received the same value for $\mathrm{AWC}, \mathrm{CT}$, and $\mathrm{CV}$ corresponding to that time unit. The number of times book reading occurred in the same time unit with other activities ranged from 12 to 18 percent (book reading \& toy play: $12 \%$, book reading \& personal care: $12 \%$, book reading \& singing songs: $15 \%$, and book reading \& mealtime: $18 \%)$. Therefore, the overlap of activities is not expected to significantly influence the comparison of the target activity book reading with other activities.

\section{Results}

Frequency of activities

The frequency of parent-child activities during the first recording day are presented in Table 2. Not all parents read a book to their child during the coded 5-minute units: 22 out of 43 parents read at least once with their child (51\%). The mean number of book reading activities coded for this group was 1.50 , which is an indication for the number of times this activity took place during the recording day. Toy play with parent was more common: 84 percent of the parents performed this activity with an average of 2.19 times a day. Singing a song or a nursery rhyme was done by 77 percent of the parents with an average of 2.79 times a day. The most common activities were mealtime (100\%) and personal care $(98 \%)$, which both took place about 4 times a day. As expected, meal time and personal care occurred most frequently over the day, followed by singing songs and toy play, while book sharing was least frequent.

\section{Differences in language input as a function of activity}

We calculated $z$-scores for each language measure (AWC, CT, and CV) separately in order to make a clear comparison between activities. For example, the calculation of the z-scores for AWC were based on the absolute AWC scores for all activities on the first recording day. There was one outlier on the AWC for singing songs causing the distribution to deviate from normal, which was therefore winsorized (Wilcox, 2016). An ANOVA with $z$-scores of AWC, CT, and CV as repeated measures and activity as between-subjects' variable was carried out to test the main effect of activity. Activity 
Table 2. Overview of the number of participants per activity and the mean daily frequency of the activity for the first recording day

\begin{tabular}{lcccc}
\hline Activity & $N^{a}$ & $M^{b}$ & $S D$ & $95 \% \mathrm{Cl}^{\mathrm{c}}$ \\
\hline Book reading & $22(51 \%)$ & 1.50 & 0.67 & {$[1.20,1.80]$} \\
\hline Toy play & $36(84 \%)$ & 2.19 & 1.43 & {$[1.71,2.68]$} \\
\hline Singing songs & $33(77 \%)$ & 2.76 & 2.17 & {$[1.99,3.53]$} \\
\hline Mealtime & $43(100 \%)$ & 4.63 & 1.79 & {$[4.08,5.18]$} \\
\hline Personal care & $42(98 \%)$ & 3.90 & 2.06 & {$[3.26,4.55]$} \\
\hline
\end{tabular}

Notes. a) total $N=43$

b) mean frequency of the per 5-minute unit coded activities for $N$ participants who performed the activity during the first recording day

c) $\mathrm{Cl}=$ Confidence Interval

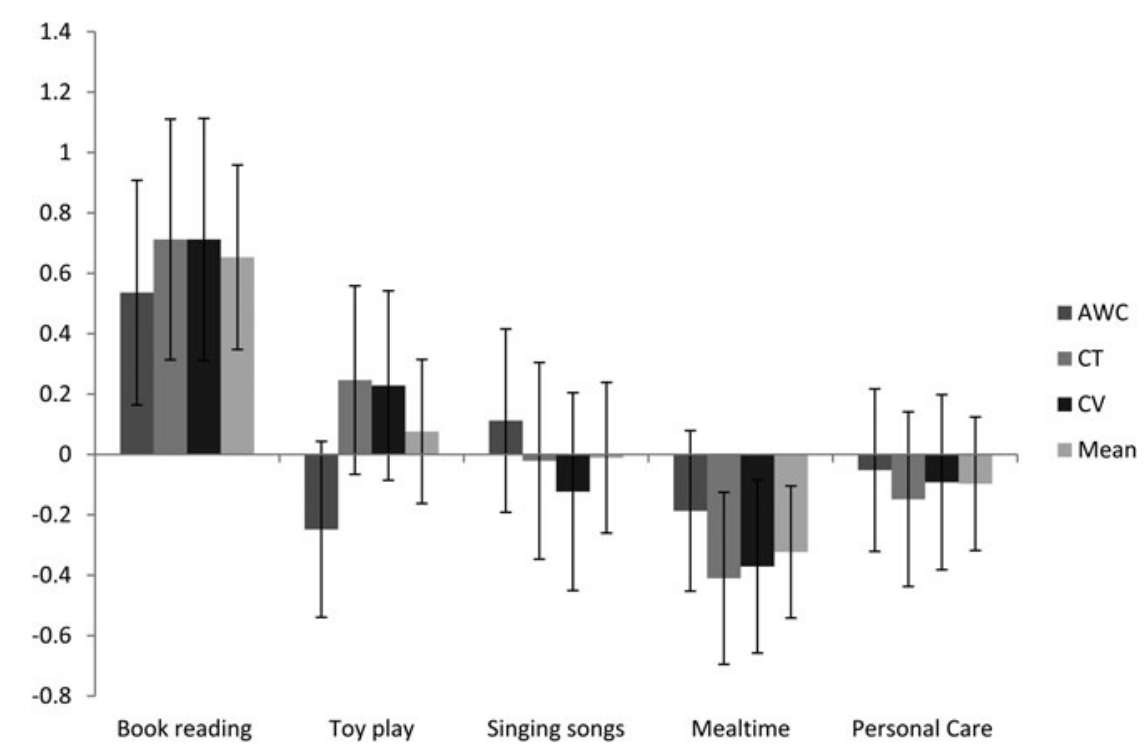

Figure 1. Mean z-scores and corresponding $95 \% \mathrm{Cl}$ of the independent language scores: Adult Word Count (AWC), Conversational Turns (CT), Child Vocalizations (CV), and the mean language score per activity $(N=22)$

had a significant main effect $\left(F(4,171)=6.87, p<.001, \eta_{\mathrm{p}}^{2}=0.14\right)$, indicating that the language use differed across activities. According to post-hoc tests, book reading scored significantly higher on the grand mean of the language measures compared to the other activities, while the other activities did not significantly differ from each other (Figure 1). These tests only included a part of all participants: the 22 parents who read a book to their child during the coded fragments. This selection of parent-child dyads did not significantly differ from the non-reading dyads on age or language scores of the other common activities (see Table 3 ). So the reading group was not older or more talkative than the non-reading group. 
Table 3. Absolute mean scores and standard deviations of the language measures for each activity, separately displayed for reading and non-reading group on the first recording day

\begin{tabular}{|c|c|c|c|c|c|c|}
\hline Activity & \multicolumn{3}{|c|}{ Reading group ${ }^{a}$} & \multicolumn{3}{|c|}{ Non-reading group ${ }^{b}$} \\
\hline Book reading & 218.37 (134) & $8.36(6.1)$ & $25.13(16.9)$ & - & - & - \\
\hline Toy play & $144.54(79.1)$ & $6.45(3.6)$ & $20.59(9.4)$ & $128.82(79.9)$ & $6.89(4.5)$ & $19.54(11.5)$ \\
\hline Singing songs & $188.63(119.7)$ & $5.62(3.6)$ & $16.55(9.6)$ & $155.52(62.3)$ & $5.70(2.3)$ & $16.49(7.9)$ \\
\hline
\end{tabular}

Notes. AWC $=$ Adult word count, $\mathrm{CT}=$ Conversational turns, $\mathrm{CV}=$ Child vocalizations

a) $N=22, \mathrm{M}$ age $=13.59(\mathrm{SD}=2.48)$

b) $N=21, \mathrm{M}$ age $=13.10(\mathrm{SD}=3.18)$ 


\section{Invited shared book reading and toy play}

We tested whether the language use initiated by instructed reading and toy play (second day) differed from the spontaneous occurrence of these activities (first day). Most parents followed up to the invitation to read to the infant and to play together on the second day. Three parents did not perform either activity and two parents performed only one resulting in a sample of 38 families. We performed one ANOVA with absolute scores of AWC, CT, and CV on day 1 and day 2 as repeated measures, activity as between-subjects' variable, and age as covariate. We used absolute LENA data, since the data set contains two measure points in time from the same children (see Table 4). This repeated measure ANOVA did reveal a main effect of activity $\left(F(1,49)=11.40, p<.001, \eta_{\mathrm{p}}^{2}=.19\right)$, indicating that the grand mean of the language measures is significantly higher for book reading $(M=94.68, S E=6.51)$ than for toy play $(M=67.08, S E=4.94)$. No main effect of age was found $(F(1,49)=.03, p=.88$, $\eta_{\mathrm{p}}^{2}=.001$ ). As the assumption for sphericity was violated (Mauchly's $\mathrm{W}=.02, \chi^{2}(2)$ $=186.14, p<.001)$ the Greenhouse-Geisser correction was used for the within-subject test. This test showed a significant interaction between the activity and language measure $\left(F(1.02,49.51)=14.02, p<.001, \eta_{\mathrm{p}}^{2}=0.22\right)$. As the scores in Figure 2 show, shared book reading had a significant higher AWC score compared to toy play, while $\mathrm{CT}$ and $\mathrm{CV}$ scores were comparable for the two activities. No main or interaction effects for time were found ( $p$ 's $>.05$ ), meaning that no differences were found in language scores between the typical day (first day) and the instructed day (second day), when corrected for age.

\section{Discussion}

Nowadays parents are encouraged to engage in language activities with their young children like singing songs, playing with toys, and book reading assuming these activities to be equally effective in enhancing language development. However, our study showed that common activities like singing songs, toy play, personal care, and mealtime all elicited a significantly lower level of language use and interaction between parent and child compared to shared book reading. Not just adult language

Table 4. Absolute mean scores and standard deviations of the language measures for book reading and toy play at recording day 1 (typical day) and 2 (instructed day).

\begin{tabular}{|c|c|c|c|c|c|}
\hline \multirow[b]{2}{*}{ Activity } & \multirow[b]{2}{*}{ LENA measure } & \multicolumn{2}{|c|}{ Day 1} & \multicolumn{2}{|c|}{ Day 2} \\
\hline & & $M$ & $S D$ & M & $S D$ \\
\hline \multirow[t]{3}{*}{ Book reading $^{a}$} & AWC & 220.27 & 141.42 & 280.61 & 101.24 \\
\hline & CT & 8.68 & 6.40 & 9.62 & 5.79 \\
\hline & $\mathrm{CV}$ & 26.75 & 17.44 & 22.27 & 15.59 \\
\hline \multirow[t]{3}{*}{ Toy play ${ }^{b}$} & AWC & 139.35 & 81.32 & 196.59 & 87.34 \\
\hline & CT & 6.66 & 4.13 & 11.47 & 5.57 \\
\hline & $\mathrm{CV}$ & 20.15 & 10.27 & 28.19 & 12.16 \\
\hline
\end{tabular}

Notes: $\mathrm{AWC}=$ Adult word count, $\mathrm{CT}=$ Conversational turns, $\mathrm{CV}=$ Child vocalizations ${ }^{\mathrm{a}} N=19,{ }^{\mathrm{b}} \mathrm{N}=38$. 


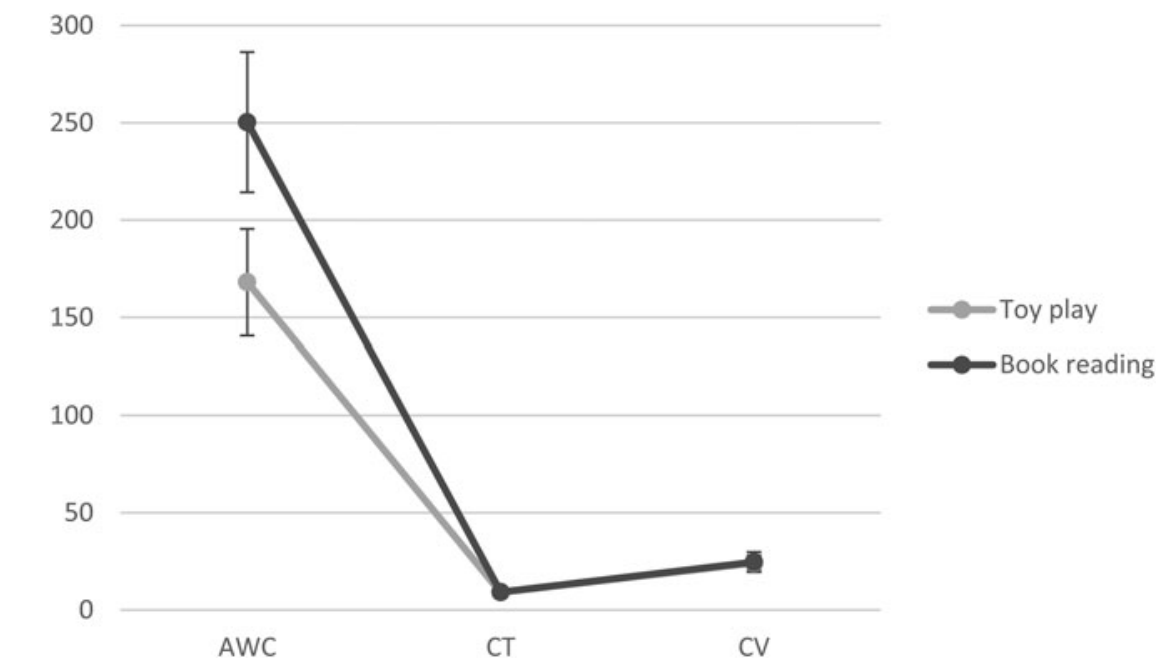

Figure 2. Interaction of activities and language measure (absolute scores of Adult Word Count (AWC), Conversational Turns (CT), and Child Vocalizations (CV) and 95\% confidence interval) at recording day $2(N=38)$

but the children's vocalizations and conversational turns all seem key to the positive influence of book reading on the language development of children (Hart \& Risley, 1995; Suskind et al., 2015). In addition we show that book reading is an effective language enhancing activity for children as young as 9 months old. Book reading seems to provide a script or guideline for parents and children which stimulates rich language from the adult as well as from the child (Sosa, 2016).

In our study we aimed to create a naturalistic environment for data collection. Language use was recorded at home in absence of observers, and parents were unaware of the main interest of the study. The LENA system made it possible to record the language used by parents and the child during all spontaneously occurring activities throughout the entire day. We were particularly interested in the comparison of book reading to other language related parent-child activities. Our results support the hypothesis that book sharing elicits more language use than any other common language related parent-infant activity, making it a rich source of quantitative language input. Also, we saw book sharing as eminently suitable for close parent child interactions, even in infants. So, book reading enhances a rich language environment for the quantitative as well as qualitative aspects of the language use, more than other language related parent-child activities.

Another argument for the strong and unique influence of shared book reading can be found in the frequency with which this activity naturally occurs. In this study, book sharing was the least frequently occurring parent-child activity in this young age group, and estimated to occur on average in 6.4 percent of the randomly selected fragments of a recording day. This is in line with previous findings, often suggesting even lower percentages as in Soderstorm and Wittebolle (2013), who found book reading to constitute 1-2 percent of a child's everyday experience. Even as shared book reading only constitutes a small amount of a child's daytime activities, the findings support our theory that this activity is an unique and strong stimulator of language use from both parent and child. This language input during book reading with young children 
predicts later language comprehension (Demir-lira et al., 2019), making it an important and valuable activity for a child's language development. So, with reasonable confidence, it can be said that time spent by parents and children on book reading is well spent quality time.

In our design we compared recordings of spontaneously occurring daily parent-child activities involving language with recordings where parents were explicitly instructed to perform language related activities: namely, reading and toy play. This design made it possible to examine whether parents act differently when they are aware of the importance of certain activities for the subject of the study. When controlling for age, there were no significant differences in language scores between the typical (first) day and the instructed (second) recording day. So, in contrast to our expectations, the explicit instructions given to the parents did not result in a significant increase of language use during the activities on day two. It seems that the familiar setting in which the language is measured lets people behave naturally. Parents did not pay close attention to the presence of the LENA recording device. Additionally, the instructions to perform well-known daily activities were minimally intrusive for the natural daily routine of parent and child. We argue that the presence of researchers and/or laboratory environment may be more intrusive to results than just a recording device and small instructions.

\section{Limitations and future directions}

In our study we used an advanced language measurement instrument, the LENA system. As mentioned earlier this system is a very effective tool to measure the naturalistic language environment of a child. However, the LENA system also has the limitation of less reliable counts of parent and child language with increasing background noise (Xu et al., 2009). This limitation does not seem to have a great influence on the current research as we focused on "quiet" activities inside the home like book sharing.

Parents were provided with a standardized traditional toy to play with on the second recording day. A traditional toy as we provided may evoke more verbal responses from the child compared to electronic toys (Sosa, 2016). Our results of the second day are in line with Sosa's (2016) that traditional toy play elicits as many parent-child interactions as book reading, but significantly less adult word input. It might be a limitation that books and toys were not standardized on both days to be better able to measure the effect of spontaneous versus instructed days. However, no standardized books were provided, due to our assumption that any children's book that both parent and child like to read is suitable for initiating parent-child interaction. Even the most simple one word per page book can generate grammatically enriched linguistic input (Noble et al., 2018). Our study shows that book reading is a powerful way to verbally interact with young children, regardless of which children's book is chosen.

Other limitations of the present study are the limited sample size and the relative homogeneity of participants by ethnicity and socioeconomic status. Parents with a higher educational level generally engage in more language enhancing activities with their children than lower educated parents (Hoff, 2006). Therefore, the relative high SES in our sample resulted in a rich dataset of spontaneous performed literacy activities during the first recording day. However, due to the homogeneity in our sample, the results of our study are limited generalizable to parent-child dyads of low(er) SES families or different ethnicities. The question whether results would 
differ for families from more diverse demographic backgrounds is an important one that remains to be answered. Given that cultural and socioeconomic factors are known to influence both the amount of time spent engaged in parent-child play and the nature of the play interaction (Bus, Leseman \& Keultjes, 2000; Pungello, Iruka, Dotterer, Mills-Koonce \& Reznick, 2009), it is important to acknowledge that the effect of toy type on parent-infant communication may be different for parents from different cultural and economic backgrounds. It is possible that more scripted activities like book reading reveal more similar outcomes in low- and high educated families as compared to parent-child play. During play parents have more room for their own interpretation, making it more dependent on parents' abilities to enrich their input. Book reading may prompt and guide the parental language use to a higher level.

\section{Conclusions}

Early language stimulation is necessary to build a solid foundation for subsequent language development. One-to-one interactions between parent and child are needed to build this neural framework. Even with children as young as 9 months old, book reading strongly promises to increase parental language input, parent-child verbal interaction, as well as verbal responses from the child. We therefore strongly advise researchers and clinical practitioners to find effective ways to motivate parents to start reading to their children as early as possible. The LENA system is recommended for research in home settings. Since small instructions do not influence the language used by parents, it is possible to measure naturalistic language environments while setting small conditions for a well-designed experiment. This procedure is strongly preferred to controlled conditions involving the presence of a researcher and/or laboratory conditions.

Acknowledgements. This study was supported by an academy Sara van Dam Project Grant awarded to dr. C.A.T. Kegel.

\section{References}

Bus, A. G., Leseman, P. P. M., \& Keultjes, P. (2000). Joint book reading across cultures: A comparison of Surinamese-Dutch, Turkish-Dutch, and Dutch parent-child dyads. Journal of Literacy Research, 32(1), $53-76$.

Canault, M., Le Normand, M., Foudil, S., Loundon, N., \& Thai-Van, H. (2016). Reliability of the language environment analysis system (LENA ${ }^{\mathrm{TM}}$ ) in European French. Behavior research methods, 48 (3), 1109-1124.

Demir-Lira, O. C., Applebaum, L. R., Goldin-Meadow, S., \& Levine, S. C. (2019). Parents early book reading to children; Relation to children's later language and literacy outcomes controlling for other parent language input. Developmental Sciences, 22, e12764.

Farrant, B. M., \& Zubrick, S. R. (2012). Early vocabulary development: The importance of joint attention and parent-child book reading. First Language, 32(3), 343-364.

Flack, Z. M., Field, A. P., \& Horst, J. S. (2018). The effects of shared storybook reading on word learning: A meta-analysis. Developmental psychology, 54(7), 1334.

Ford, M., Baer, C. T., Xu, D., Yapanel, U., \& Gray, S. (2008). The LENA language environment analysis system: audio specifications of the DLP-0121. Boulder, CO:LENA Foundation.

Gilkerson, J., \& Richards, J. A. (2008). The LENA natural language study. Boulder, CO:LENA Foundation.

Gilkerson, J., Richards, J. A., \& Topping, K. J. (2017). The impact of book reading in the early years on parent-child language interaction. Journal of Early Childhood Literacy, 17(1), 92-110. 
Gilkerson, J., Richards, J. A., Warren, S. F., Oller, D. K., Russo, R., \& Vohr, B. (2018). Language experience in the second year of life and language outcomes in late childhood. Pediatrics, 142 (4), 1-11.

Greenwood, C. R., Thiemann-Bourque, K., Walker, D., Buzhardt, J., \& Gilkerson, J. (2011). Assessing children's home language environments using automatic speech recognition technology. Communication Disorders Quarterly, 32(2), 83-92.

Hart, B., \& Risley, T. (1995), Meaningful differences in the everyday experience of young american children. Baltimore, MD: Brookes Publishing.

Hoff, E. (2006). How social contexts support and shape language development. Developmental review, 26 (1), 55-88.

Kuhl, P. K. (2004). Early language acquisition: Cracking the speech code. Nature Reviews Neuroscience, 5 , 831-843.

Logan, J. A. R., Justice, L. M., Yumuş, M., \& Chaparro-Moreno, L. J. (2019). When children are not read to at home: The million word gap. Journal of Developmental \& Behavioral Pediatrics. Advance online publication. Doi:10.1097/DBP.0000000000000657

Mol, S. E., \& Bus, A. G. (2011). To read or not to read: A meta-analysis of print exposure from infancy to early adulthood. Psychological bulletin, 137(2), 267.

Mol, S. E., Bus, A. G., de Jong, M. T., \& Smeets, D. J. H. (2008). Added value of dialogic parent-child book readings: a meta-analysis. Early Education and Development, 19(1), 7-26.

Montag, J. L., Jones, M. N., \& Smith, L. B. (2015). The words children hear: picture books and the statistics for language learning. Psychological science, 26(9), 1489-1496.

Noble, C. H., Cameron-Faulkner, T., \& Lieven, E. (2018). Keeping it simple: the grammatical properties of shared book reading. Journal of child language, 45(3), 753-766.

Noble, C., Sala, G., Peter, M., Lingwood, J., Rowland, C., Gobet, F., \& Pine, J. (2019). The impact of shared book reading on children's language skills: A meta-analysis. Educational Research Review, 28, 100290.

Ramírez-Esparza, N., García-Sierra, A., \& Kuhl, P. K. (2014). Look who's talking: speech style and social context in language input to infants are linked to concurrent and future speech development. Developmental science, 17(6), 880-891.

Rowe, M. L. (2012). A longitudinal investigation of the role of quantity and quality of child directed speech in vocabulary development. Child development, 83(5), 1762-1774.

Rowe, M. L., \& Zuckerman, B. (2016). Word gap redux: Developmental sequence and quality. JAMA Pediatrics, 170, 827-828.

Pungello, E. P., Iruka, I. U., Dotterer, A. M., Mills-Koonce, R., \& Reznick, J. S. (2009). The effects of socioeconomic status, race, and parenting on language development in early childhood. Developmental psychology, 45(2), 544-557.

Sosa, A. V. (2016). Association of the type of toy used during play with the quantity and quality of parent-infant communication. JAMA pediatrics, 170(2), 132-137.

Soderstrom, M., \& Wittebolle, K. (2013). When do caregivers talk? The influences of activity and time of day on caregiver speech and child vocalizations in two childcare environments. PLOS ONE, 8(11), e80646.

Suskind, D., Suskind, B., \& LeWinter-Suskind, L. (2015). Thirty million words: Building a child's brain. New York: Dutton.

Tamis-LeMonda, C. S., Kuchirko, Y., Luo, R., Escobar, K., \& Bornstein, M. H. (2017). Power in methods: language to infants in structured and naturalistic contexts. Developmental Science, 20(1), 1-14.

Tierney, A. L., \& Nelson, C. A. (2009). Brain development and the role of experience in the early years. Zero to three, 30, 9-13.

Warlaumont, A. S., Richards, J. A., Gilkerson, J., \& Oller, D. K. (2014). A social feedback loop for speech development and its reduction in autism. Psychological science, 25(7), 1314-1324.

Weisleder, A., \& Fernald, A. (2013). Talking to children matters early language experience strengthens processing and builds vocabulary. Psychological science, 24(11), 2143-2152.

Whitehurst, G. J., Falco, F. L., Lonigan, C. J., Fischel, J. E., DeBaryshe, B. D., Valdez-Menchaca, M. C., \& Caulfield, M. (1988). Accelerating language development through picture book reading. Developmental psychology, 24(4), 552.

Wilcox, R. R. (2016). Introduction to robust estimation and hypothesis testing. London: Academic press.

Xu, D., Yapanel, U., \& Gray, S. (2009). Reliability of the LENA ${ }^{\mathrm{TM}}$ language environment analysis system in young children's natural home environment. Boulder, CO: LENA Foundation. 
Xu, D., Yapanel, U., Gray, S., Gilkerson, J., Richards, J. A., \& Hansen, J. (2008, October). Signal processing for young child speech language development. In WOCCI (p. 20).

Zimmerman, F. J., Gilkerson, J., Richards, J. A., Christakis, D. A., Xu, D., Gray, S., \& Yapanel, U. (2009). Teaching by listening: the importance of adult-child conversations to language development. Pediatrics, 124(1), 342-349.

Cite this article: Clemens LF, Kegel CAT (2021). Unique contribution of shared book reading on adultchild language interaction. Journal of Child Language 48, 373-386. https://doi.org/10.1017/ S0305000920000331 